\title{
Reconstructive Microsurgery in the Cedars Land - Lebanon
}

\author{
Joseph Bakhach*, Elsa Bakhach and Bachar Chaya \\ Division of Plastic \& Reconstructive Surgery, Hand \& Microsurgery, American University of Beirut Medical Center, Lebanon
}

Received: 制 August 22, 2018; Published: 漹 August 29, 2018

*Corresponding author: Bakhach J, American University of Beirut Medical Center, P.O.Box 11-0236, Riad El-Solh, Beirut 1107-2020, Lebanon

\begin{abstract}
Lebanon is a small country situated on the eastern border of the Mediterranean Sea. It is located in an area of never ending wars and conflict. It is also one of the leading middle eastern countries for medical tourism. The American University of Beirut Medical Center (AUBMC) is one of the biggest tertiary centers in the Middle East North Africa region. As a result, most of the major traumas that require microsurgical expertise, are referred to our center. The management of a patient presenting to us as a result of conflict is completely different from the management of a patient presenting, for the same procedure, in a first world country. Hence, our region and country require Plastic Surgeons that are well trained in Reconstructive Microsurgery. In AUBMC, we aim to establish the first microsurgical training program in the region.
\end{abstract}

\section{Introduction}

Lebanon is a small country situated on the eastern border of the Mediterranean Sea. It has a surface area of $10452 \mathrm{Km} 2$ and a total population of 6.1 million. Of these 6 million inhabitants, 4.1 million are citizens, and the remaining 2 million are refugees (Syrians and Palestinians) [1]. The medical level of the country is relatively advanced with 80 specialized plastic and reconstructive surgeons and around 600 specialized orthopedic and reconstructive trauma surgeons [2]. The majority of the aforementioned, received high level of education and training in major and well renowned centers in Northern America and Europe [2]. In addition, Lebanon comprises six universities that graduate students in all medical specialties, giving them an expertise equivalent to the highest international programs. One of these universities, and the oldest, is the American University of Beirut (AUB), founded in 1886 and sought after by many students from Lebanon and nearby Arab countries in order to acquire the high educational level and specialized training that this institution provides. This university is affiliated with one of the biggest medical centers in the region [3]. It has well advanced technological equipment and is well recognized within the scientific community. This combination of highly specialized training and well-equipped centers puts Lebanon on the map as a medical destination, luring patients from nearby and distant countries such as Syria, Iraq, Egypt, and Gulf countries [4]. In addition, it also provides care to Lebanese emigrants, whose number exceeds the Lebanese population by 4 times, whenever they are visiting their native country.

\section{Medical care in Lebanon}

In light of the political situation, the medical coverage and social security system in Lebanon is deficient. We rely mainly on multiple public organizations aided by several other complimentary organizations of the private sector [5]. Nevertheless, these public organization, have limited financial coverage with delays in the hospital reimbursement process. This is mainly due to the elevated cost of medical care in this country that parallels a ministry of health that has very minimal resources [6]. Private insurance companies are expensive and cover less than $7 \%$ of the total Lebanese population. These social coverages and insurance institutions represent a lobby of business-oriented personnel that have minimal professional conscience and medical deontology. As a Plastic and Reconstructive Surgeon specialized in Hand and Microsurgery, I have faced several situations that can be qualified as immoral. I was presented on several occasions with patients suffering from complete digital amputations requiring microvascular reimplantation but nevertheless were not covered by any insurance.

These patients preferred to lose their finger rather than reimplanting it based on the fact that the surgery is much more expensive than amputation. As a consequence of the economic and financial crises that Lebanon is currently facing, most of our population will have difficulty in affording the expenses of microsurgical procedure alongside the expenses of tertiary care centers. On the other hand, the financially stable and relatively rich 
individuals coming from the Gulf countries and Iraq, some of which are Lebanese in origin, are able to afford the high-cost medical care and the expensive surgical procedures. This social injustice has strongly contributed to the formation of a chaotic sanitary and medical situation, preventing physicians across the country to become involved in highly specialized centers. In spite of this trend, operations requiring high levels of expertise and an advanced level of care, such as finger reimplantation surgeries and free-flaps, are still confined to tertiary referral centers such as the American University of Beirut Medical Center (AUBMC) which excels in giving adequate treatment and postoperative care to the patients involved. We encounter an average of 80 to 90 microsurgical procedures a year. Other university-affiliated centers might also perform these types of procedures; however, the frequency of these cases is clearly lower.

\section{Microsurgery in Lebanon}

As you already know, the practice of Reconstructive Microsurgery necessitates a long and tedious learning process, which includes the acquisition of the basic surgical principles encountered by rotating first in General Surgery and later on in Plastic and Reconstructive Surgery. The acquisition of the correct skills and the ability to successfully perform these tedious and challenging operations relies on the surgical endowment of the surgeon and on his experience. Despite the fact that Reconstructive Microsurgery is the Michael Angelo of plastic surgery, allowing the repair of what an accident had destroyed or what a tumor had devoured, it is sad to say that the majority of the Plastic Surgeons in Lebanon have chosen to abandon Reconstructive and Microsurgery in favor of the more lucrative and less tedious Aesthetic Surgery. Actually, Lebanon contains very few microsurgeons; three of which are working at the American University of Beirut Medical Center (AUBMC). After twelve years of private surgical practice abroad in a specialized center in Hand and Reconstructive Microsurgery, I returned to my native country and joined AUBMC.

We subsequently created the "Hand and Microsurgery Unit"” within the "Plastic and Reconstructive Surgery" division. As a result, we have already performed several microsurgical procedures to reconstruct defects on the face and extremities sustained by blast injuries. These injuries generated complex defect with composite loss of various amounts of tissues that resulted in anatomic deformities. Unfortunately, the majority of these cases are referred to us from the zones of conflicts that lie in our neighboring countries Syria and Iraq.

The particularity of these post-blast injuries, as compared to the classical traumatic lesions, resides in the fact that a bomb explosion entails several additional phenomena:

a) The shock sustained by the body due to shrapnel injuries is exacerbated by the kinetic effect of the fragments on the superficial and deep anatomic structures, in particular those within the crush and tear zones.

b) The thermal effect that is produced by the contact and passage of shrapnel through the tissues, causing soft tissue burns. c) Finally, the blast waves produced by the explosion, particularly if in proximity to the body (Bomb Maker injuries), causes soft tissue loss [7].

Since different mechanisms of injury causes different types of tissue damage, it is fundamental to recognize the mechanism of injury. There is always a need for a complete physical examination of the different anatomic, neural and vascular structures that lies in proximity to the site of injury [8]. After going through the ABC's of trauma and performing a physical exam, an extensive debridement should be done. From there on, multiple imaging modalities (CT angiogram or angiography) can be used to assess the patency of different vessels that we will eventually use as a nourishing pedicle for the free flap [9]. Moreover, most of the patients that present to us for microsurgical procedures are, as previously mentioned, from conflict areas. Hence, they present to us in the subacute or chronic phase of injury. Their early management, in their country of origin, consisted mainly of basic field resuscitations or primary care that lacks standard hygiene modalities. As a result, most of these poorly treated wounds are colonized or infected by multiresistant organisms. As they present to us, local wound care and broad-spectrum antibiotics are advised until the status of the wound improves.

Once the wound is clean and started healing, a long and complex microsurgical reconstructive plan is initiated [10]. In addition to our surgical activity, our mission in Lebanon, and at the American University of Beirut Medical Center (AUBMC) in particular, is to supply the upcoming generations of plastic surgeons with the essential skills and expertise to become excellent microvascular surgeons. This is why we have initiated a microsurgical training course at our faculty of medicine. The aim of this course is to teach the basic techniques of the vascular microsurgical suturing alongside the different vascular anastomotic types that our residents will eventually need to know. We are also planning to start an advanced course in microsurgery. This course will deal with more advanced situations that the residents might encounter later on in their practice. in addition, our trainee will be able to perform free microvascular transfers on rats once our lab is finally equipped for these procedures.

\section{Conclusion}

With these small steps that we have taken, we have installed the building blocks of a successful hand and microsurgical program. Nevertheless, our mission will not stop here. A regional upper extremity and hand allotransplantation program is still missing. We are planning on laying the grounds for this program as well. All these actions should be completed in the near future in order to offer the best standard of care to both Lebanese and foreign patients presenting with these types of injuries. The journey is long, and our steps are dismal. Nevertheless, our hopes are high, aiming to establish a tertiary care and referral unit capable of assimilating a high load of patients with complex injuries, in this part of the world engaged in never ending wars.

\section{References}

1. Ammar W, Ola Kdouh, Rawan Hammoud, Randa Hamadeh, Hilda Harb, et al. (2016) Health system resilience: Lebanon and the Syrian refugee crisis. J Glob Health 6(2): 020704. 
2. Kassak KM, Hassan MK Ghomrawi, Arabia Mohamad Ali Osseiran, Hanaa Kobeissi (2006) The providers of health services in Lebanon: a survey of physicians. Hum Resour Health 4: 4.

3. Mc DJ (1958) The American University of Beirut School of Medicine. J Med Educ 33(11): 761-770.

4. Jabbour S, Jennifer Leaning, Iman Nuwayhid, Richard Horton, Pamela Das (2016) The Lancet-American University of Beirut Commission on Syria: a new role for global health in conflict and a call for papers. Lancet 388(10063): 2967-2968.

5. El Jardali F, Bou Karroum L, Ataya N, El Ghali HA, Hammoud R (2014) A retrospective health policy analysis of the development and implementation of the voluntary health insurance system in Lebanon: learning from failure. Soc Sci Med 123: 45-54.

ISSN: 2574-1241

DOI: 10.26717/BJSTR.2018.08.001657

Bakhach J. Biomed J Sci \& Tech Res

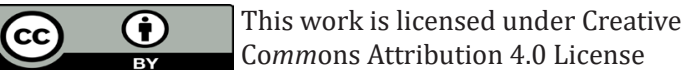

Submission Link: https://biomedres.us/submit-manuscript.php
6. Al Ghul A (1980) The demographic and economic consequences of the civil war in Lebanon. Samid Aliqtisadi 3(18): 119-128.

7. Sheean AJ, Tintle SM, Rhee PC (2015) Soft tissue and wound management of blast injuries. Curr Rev Musculoskelet Med 8(3): 265-271.

8. Bakhach J, Abu-Sitta G, Dibo S (2013) Reconstruction of blast injuries of the hand and upper limb. J of Injury 44(3): 305-312.

9. Bakhach J, Abou Ghanem O, Bakhach D, Zgheib E (2017) Early free flap reconstruction of blast injuries with thermal component. Ann of Burns and Fire Disasters 30(4): 303-308.

10. Singer AJ, Dagum AB (2008) Current management of acute cutaneous wounds. N Engl J Med 359(10): 1037-1046.

$\begin{array}{ll}\text { BIOMEDICAL } & \text { Assets of Publishing with us } \\ \text { RESEARCHES } & \text { - Global archiving of articles } \\ & \text { - Immediate, unrestricted online access } \\ & \text { - Rigorous Peer Review Process } \\ \end{array}$

